Archives of Agriculture and Environmental Science

\title{
Genetic diversity analysis of some Bangladeshi aromatic rice (Oryza sativa L.) using simple sequence repeat markers (SSRM)
}

\author{
Md. Ashraful Islam ${ }^{1}$ Touhidur Rahman Anik ${ }^{2 *}$ iD, Mohammad Monjur Hossain ${ }^{3}$, Md. Imtiaz \\ Uddin $^{1}$ and Md. Shahabuddin Ahmed ${ }^{2}$ \\ ${ }^{1}$ Biotechnology Division, Bangladesh Institute of Nuclear Agriculture (BINA), Mymensingh - 2202, BANGLADESH \\ ${ }^{2}$ Department of Biotechnology, Bangladesh Agricultural University (BAU), Mymensingh - 2202, BANGLADESH \\ ${ }^{3}$ Department of Agronomy, Bangladesh Agricultural University (BAU), Mymensingh - 2202, BANGLADESH \\ "Corresponding author's E-mail: anikbge@gmail.com
}

\section{ARTICLE HISTORY}

Received: 15 August 2018

Revised received: 23 August 2018

Accepted: 27 August 2018

\section{Keywords}

Aromatic rice

Breeding

Cluster analysis

Genetic diversity

SSR marker

\begin{abstract}
In order to germplasm management, conservation, parental identification and proper utilization of aromatic rice germplasm of Bangladesh genetic diversity assessment and molecular characterization is necessary. We used ten microsatellite markers across twenty aromatic rice landraces along with four improved varieties to discriminate and characterize among them. The number of alleles per locus ranged from 2 to 8, with an average of 4.30 alleles across 10 loci. A total of 43 polymorphic alleles were detected. The values of Polymorphic information content (PIC) ranged from 0.217 to 0.835 (average 0.495 ) which indicate high genetic diversity among the studied aromatic rice genotypes. It was concluded by the PIC value of RM5339 that it might be the finest marker for diversity estimation and characterize of these aromatic rice genotypes, followed by RM334, RM414 and RM28502 markers. The UPGMA cluster dendrogram constructed in this study identified seven clusters with a correlation coefficient 0.874 . Molecular characterization of aromatic rice landraces of Bangladesh exhibited large variations among the genotypes. Five rice genotypes namely BRRI dhan38, BRRI dhan50, Bashmoti safed, Malaysira, Khas-kani showed highest genetic dissimilarity among the studied rice genotypes. The findings of this study would be useful for background selection in backcross breeding programs for aromatic rice improvement as well as identification of genetically distant and genetically close accessions for maintenance and conservation.
\end{abstract}

(C)2018 Agriculture and Environmental Science Academy

Citation of this article: Islam, M.A., Anik, T.R., Hossain, M.M, Uddin, M.I. and Ahmed, M.S. (2018). Genetic diversity analysis of some Bangladeshi aromatic rice (Oryza sativa L.) using simple sequence repeat markers (SSRM). Archives of Agriculture and Environmental Science 3(3): 297-303, https://dx.doi.org/10.26832/24566632.2018.0303013

\section{INTRODUCTION}

Rice (Oryza sativa L.) is a cereal grain and it is the most widely consumed staple food for a large part of the world's human population, especially in Asia. Around the world rice is cultivated in approximately hundred countries covering almost 158 million hectares of cultivated land and its annual production is above 700 million tons (Anonymous, 2018). Rice cultivation is well-suited to countries and regions with low labor costs and high rainfall, as it is labor-intensive to cultivate and requires ample water. As a result, rice occupies about $70 \%$ of the total cropped area of about 13.9 million hectares in Bangladesh (Sajib et al., 2012).

Aromatic rice is a small sub-group of rice. In several aromatic rice varieties an aroma component 2-acetyle-I-pyrroline (similar to popcorn), has been found as an imperative flavor component (Weber et al., 2000). The aroma, flavor and texture of aromatic rice make it high graded in quality and so procure higher price compared to high quality non-aromatic rice in international market. For example, Aromatic rice such as Basmati from Pakistan, Nepal, and India and Sadri from Iran are highly valued for their aroma and quality (Garris et al., 2005). Aromatic rice is widely accepted not only in Asia but also in Europe and USA 
(Sajib et al., 2012). Though their high importance, improvement of aromatic rice has been relatively slow. Historically, aromatic rice are cultivated in small areas of Bangladesh. According to conventional taxonomy, Bangladeshi (Indian sub-continent) aromatic rice have been identified as indicas (Khush et al., 2000). Most of the aromatic landraces are low yielding and medium fine grain with strong aroma. After introduction of high yielding rice varieties, the cultivation of land races reduced drastically. As a result, a many aromatic rice as well as other land races have already been lost and many are at the verge of extinction (Singh et al., 2000). But these native rice varieties traditionally cultivated by farmers may contain a substantial genetic diversity which can be a source of germplasm for genetic enhancements of cultivated rice varieties (Choudhury et al., 2013).

Traditionally morphological or physiological traits as well as protein or isozyme markers are used to assess genetic diversity in plants. But they are greatly biased by environment, need long time for assessment and show low polymorphism between the genotypes (Chakravarthi and Naravaneni, 2006). In contrast, modern biotechnology provide us molecular markers which are independent of environmental factors, show high polymorphism between the genotypes, allow easy and quick analysis of loci distributed among the plant genome (Chakravarthi and Naravaneni, 2006). As a result, molecular markers have become distinct, reliable and efficient tool for characterization, conservation, management of germplasm. Among the PCR based DNA markers, microsatellites or SSRs (simple sequence repeats) are highly preferred for gene tagging and gene mapping efforts as they have high level of polymorphism content and versatility. They are tandemly repeats of simple sequence which may be a short motif of di, tri, or tetra-nucleotides (Li et al., 2004). SSR markers are also preferred in genetic diversity analysis, molecular map construction and genetic mapping, construction of fingerprinting, genetic purity test, analysis of rice lines diversity test etc. due to their reproducibility and amenability for automation, quickness, simplicity, rice polymorphism stability, accuracy etc. (McCouch et al., 2002; Ma et al., 2011; Roy et al., 2015). Genetically distant and the morphologically close accessions could also be identified by SSR markers (Sajib et al., 2012). In the present study, twenty aromatic landraces of Bangladesh along with four improved aromatic varieties were analyzed for genetic variation using SSR markers. The special objective was to find out genetic diversity and relationship of aromatic landraces, to assist in base broadening of the germplasm for future aromatic rice breeding programs.

\section{MATERIALS AND METHODS}

\section{Collection of genetic materials}

Experimental material comprised of 20 aromatic rice landraces and 4 improved varieties. List of genotypes with their type, origin, source of collection, kernel size and shape and aroma type are given in Table 1. These rice genotypes were collected from Bangladesh Institute of Nuclear Agriculture, BINA, Maymensingh and Bangladesh Rice Research Institute, BRRI, Gazipur.

\section{Methods for SSR genotyping}

DNA was extracted from the leaf tissues of 21 days old seedlings (a single seedling per genotype), based on a modified acetyl trimethyl ammonium bromide (CTAB) method described by (Stein et al., 2001). Twelve SSR markers, one from each chromosome were selected. Among them the primers that showed polymorphic band were selected and primers that showed monomorphic band were excluded. Finally, 10 microsatellite primers were selected for final PCR amplification. Detailed information of the primers we used can be found in web database (http://www.genetics.org). Information about primer sequences and allele sizes is shown in Table 2. Polymerase chain reactions (PCRs) were performed in a thermo cycler (G-STROM, GSI, England). The volume of PCR solution was $10 \mu$, containing $3 \mu$ l of diluted template DNA, $1.5 \mu$ l of $10 X \times$ PCR buffer $\left(\mathrm{Mg}^{2+}\right.$ free), $0.2 \mu$ l of Taq DNA polymerase, $0.25 \mu \mathrm{l} 10 \mathrm{mM}$ of deoxynucleotide triphosphates (dNTPs), $1.8 \mu \mathrm{l}$ of $\mathrm{Mg}^{2+}$, and $0.5 \mu \mathrm{l}$ of each forward and reverse primers and $2.25 \mu$ of double distilled $\mathrm{H}_{2} \mathrm{O}$. The following PCR profile used an initial denaturation step for 5 minute at $94^{\circ} \mathrm{C}$ (hot start and stand separation). After that 35 cycles of denaturation at $94^{\circ} \mathrm{C}$ for 1 minute, 35 cycles of anneling at $55^{\circ} \mathrm{C}$ for 1 minute, 35 cycles of primer elongation at $72^{\circ} \mathrm{C}$ for 2 minute and then final elongation at $72^{\circ} \mathrm{C}$ for 5 minute. Amplified products were stored at $-20^{\circ} \mathrm{C}$. The amplified fragments were separated on $8 \%(\mathrm{w} / \mathrm{v})$ native polyacrylamide gels. The electrophoreses were performed at 70v for $2 \mathrm{~h}$ in $1 \times$ TBE [Tris-borateethylenediaminetetraacetic acid (EDTA)] buffer, and the gels were stained with ethidium bromide for 25-30 min, kept in dark, and then visualized using an Alpha-Image gel documentation unit linked to a PC

\section{Data analysis}

The most intensely amplified fragments were determined by comparing the migration distance of amplified fragments relative to the molecular weight of known size marker, 100 base pair (100bp) DNA-ladder, using Alpha-Ease FC 5.0 software (Alpha Innotech, USA). The band profiles for each SSR primer pair were scored for distinct and reproducible bands as present (1) or absent (0). Jaccard's similarity coefficient values were selected, pair wise genetic distance was calculated and dendrogram (Nei, 1973) based on similarity coefficient values were generate using unweighted pair-group method with arithmetic mean (UPGMA) by using the online dendrogram construction utility Dendro UPGMA (http://genomes.urv.es/UPGMA) (Garcia -Vallvé et al., 1999). The polymorphic information content (PIC) value was calculated using the following formula (Anderson et al., 1993):

$$
\mathrm{PIC}=1-\sum_{i=1}^{k} p_{i}^{2}
$$

Where, ' $k$ ' is the total number of alleles (bands) detected for one SSR locus and ' $p$ ' is the proportion of the cultivars or genotypes containing the allele (band) in all the samples analyzed. 


\section{RESULTS AND DISCUSSION}

\section{Overall allelic diversity}

Ten published SSR primer pairs were selected from different chromosome. These 10 primer pair generated 43 unambiguous bands with an average of 4.3 bands per primer pair. Each 43 amplified band was polymorphic. The number of polymorphic alleles per locus amplified by each primer pair ranged from 2 (primer pair 7) to 8 (primer pair 3) with an average of 4.3 alleles per locus. The SSR markers were highly informative and polymorphic as evident from its polymorphic information content or PIC value. The PIC value of each primer pair ranged from 0.217 to 0.835 with an average of 0.495 (Table 3). The level of polymorphism determined by the PIC value (mean= 0.48 ) is consistent with the reported PIC value in previous works (Wong et al., 2009; Hossain et al., 2012; Sajib et al., 2012). The highest PIC value 0.835 was obtained for primer RM5639 (Figure 1). Other primers, such as RM334 (0.655), RM414 (0.580), RM28502 (0.569) also showed high PIC value. This result raveled that marker RM5639 would be the best in screening this 24 rice genotype followed by RM334, RM414 and RM28502. However, primer RM28502 showed band pattern (Figure 2) which was very much similar to the UPGMA dendrogram constructed with the 24 aromatic rice genotypes. The PIC value found in this study indicated high genetic diversity among the studied aromatic rice germplasm. So, despite their cultivation in marginal areas, aromatic rice landraces of Bangladesh showed high genetic diversity. Similar high genetic diversi- ty among Bangladeshi aromatic rice genotypes ware observed by Sajib et al. (2012) in their genetic diversity analysis of 12 aromatic rice genotypes cultivated in Bangladesh, using SSR markers. These findings of current study were also supported by the findings of Islam et al. (2016) who used 19 quantitative traits to assess the variability of 113 aromatic rice and fine rice genotypes cultivated in Bangladesh. The diverse genetic nature of these aromatic rice landraces possibly be an echo of the prevailing diverse agro-ecological features of these region.

UPGMA cluster of 24 aromatic rice genotypes based on SSR marker analysis

An UPGMA based dendrogram was constructed from the binary data obtained from the SSR marker based DNA profiles of the sample analyzed (Figure 3). The genotypes that were genetically similar clustered together in the dendrogram. Using correlation coefficient $(C P=0.874)$ we constructed the UPGMA dendrogram of the 24 aromatic rice genotypes. We observe seven major clusters. Cluster I contained only one genotype which is BRRI dhan38. Cluster II also contained one genotype, Maloti. Cluster III consisted of 9 genotypes namely, Malaysira, Katarivogue, Dhanchicon, BRRI dhan34, Sadagura, Chinisail, BR- 5, Gobindovogue and Khas-kani. Cluster IV consisted of 5 genotypes namely, Fulkori, Begunbitchi, Radunipagol, Khasamukpura and Kalojira. Cluster $\mathrm{V}$ consisted of two genotypes namely, Oukunmodu and Khas. Cluster VI consisted of 4 genotypes namely, Basmoti Indian, Black, Dudsail and Dubsail. Cluster VII consisted of two genotypes namely, Basmoti safed, BRRI

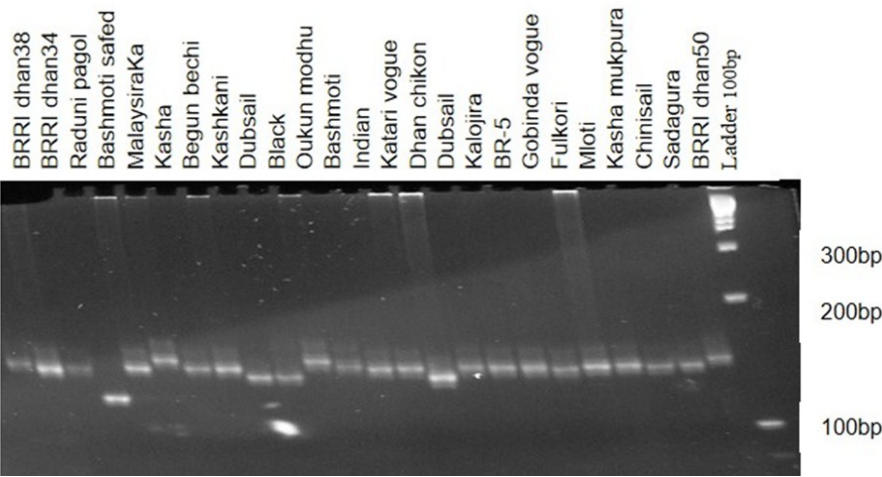

Figure 1. Amplification profile of primer RM5639 from 24 aromatic rice genotypes in $1.0 \%$ agarose gel strained with ethidium bromide. Two micro liter of PCR product was used in each sample.

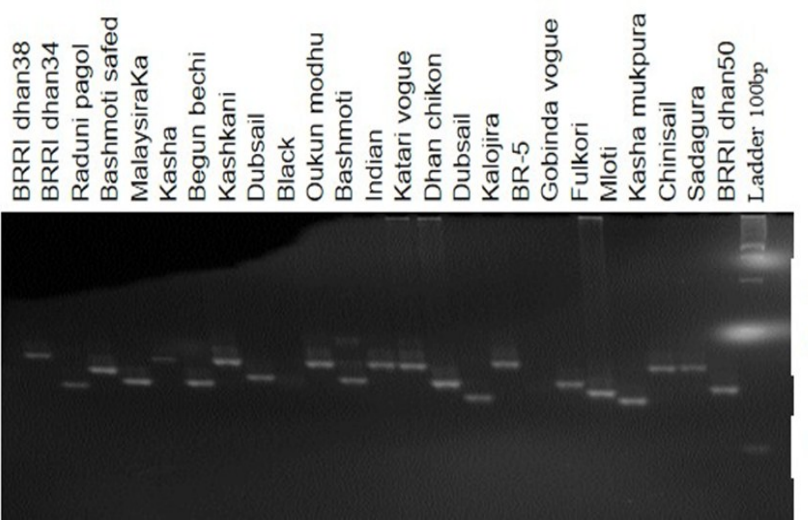

$300 \mathrm{bp}$

$200 \mathrm{bp}$

$100 \mathrm{bp}$

Figure 2. Amplification profile of primer RM5639 from 24 aromatic rice genotypes in $1.0 \%$ agarose gel strained with ethidium bromide. Two micro liter of PCR product was used in each sample.

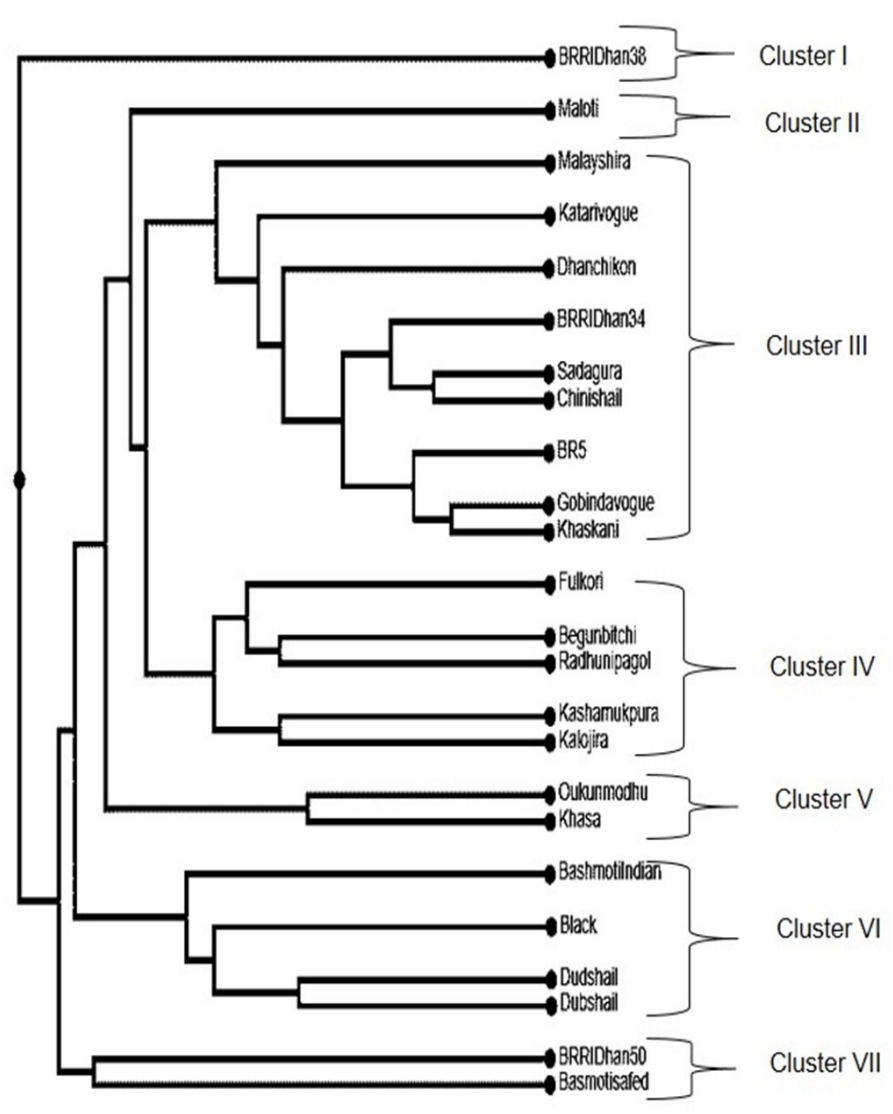

Figure 3. UPGMA cluster dendrogram in Newick Format showing genetic relationships among 24 genotypes based on 10 SSR markers. Cophenetic Correlation Coefficient (CP) value is 0.874 . 
Table 1. List of genotypes with their type, origin, source of collection, kernel size and shape and aroma type.

\begin{tabular}{|c|c|c|c|c|c|}
\hline Genotypes & Type & Origin & Source of collection & Kernel size and shape & Aroma type \\
\hline BRRI dhan38 & Improved variety & Bangladesh & BRRI & Medium, slender & Scented \\
\hline BRRI dhan34 & Improved variety & Bangladesh & BRRI & Short, medium & Scented \\
\hline Radunipagol & Land races & Bangladesh & BINA & Short, medium & Scented \\
\hline Basmoti safed & Land races & Bangladesh & BINA & Medium, slender & Lightly scented \\
\hline Malaysira & Land races & Bangladesh & BINA & Short, bold & Lightly scented \\
\hline Khasa & Land races & Bangladesh & BINA & Short, medium & Scented \\
\hline Begunbechi & Land races & Bangladesh & BINA & Short, bold & Lightly scented \\
\hline Khaskani & Land races & Bangladesh & BINA & Short, medium & Scented \\
\hline Dubsail & Land races & Bangladesh & BINA & Short, bold & Scented \\
\hline Black & Land races & Bangladesh & BINA & Short, bold & Scented \\
\hline Oukun modhu & Land races & Bangladesh & BINA & Short, medium & Scented \\
\hline Basmoti Indian & Land races & India & BINA & Long, slender & Lightly scented \\
\hline Katarivogue & Land races & Bangladesh & BINA & Short, medium & Scented \\
\hline Dhanchikon & Land races & Bangladesh & BINA & Short, medium & Lightly scented \\
\hline Dudsail & Land races & Bangladesh & BINA & Short, medium & Lightly scented \\
\hline Kalojira & Land races & Bangladesh & BINA & Short, medium & Scented \\
\hline BR-5 & Improved variety & Bangladesh & BRRI & Short, bold & Scented \\
\hline Gobindavogue & Land races & Bangladesh & BINA & Short, medium & Lightly scented \\
\hline Fulkori & Land races & Bangladesh & BINA & Short, bold & Lightly scented \\
\hline Maloti & Land races & Bangladesh & BINA & Short, medium & Lightly scented \\
\hline Khasa mukpura & Land races & Bangladesh & BINA & Short, medium & Scented \\
\hline Chinisail & Land races & Bangladesh & BINA & Short, medium & Lightly scented \\
\hline Shadagura & Land races & Bangladesh & BINA & Short, medium & Lightly scented \\
\hline BRRI dhan50 & Improved variety & Bangladesh & BRRI & Long, slender & Lightly scented \\
\hline
\end{tabular}

Table 2. Information of microsatellite markers used for molecular characterization.

\begin{tabular}{|c|c|c|c|c|}
\hline Primer name & Chromosome & Primer sequences & Locus & Expected length (bp) \\
\hline RM526 & 2 & $\begin{array}{l}\text { CCCAAGCAATACGTCCCTAG } \\
\text { ACCTGGTCATGACAAGGAGG }\end{array}$ & $(\text { TAAT })_{5}$ & 121 \\
\hline RM5639 & 3 & $\begin{array}{l}\text { GGAAGAACAGAGTTGCTCGG } \\
\text { GTGCCATTTATTTCCGTCCC }\end{array}$ & $(\mathrm{AAG})_{13}$ & 123 \\
\hline RM334 & 5 & $\begin{array}{l}\text { GTTCAGTGTTCAGTGCCACC } \\
\text { GACTTTGATCTTTGGTGGACG }\end{array}$ & $(\mathrm{CTT})_{20}$ & 182 \\
\hline RM314 & 6 & $\begin{array}{l}\text { CTAGCAGGAACTCCTTTCAGG } \\
\text { AACATTCCACACACACACGC }\end{array}$ & $(\mathrm{GT})_{8}(\mathrm{CG})_{3}(\mathrm{GT})_{5}$ & 118 \\
\hline RM234 & 7 & $\begin{array}{l}\text { ACAGTATCCAAGGCCCTGG } \\
\text { CACGTGAGACAAAGACGGAG }\end{array}$ & $(\mathrm{CT})_{25}$ & 156 \\
\hline RM407 & 8 & $\begin{array}{l}\text { GATTGAGGAGACGAGCCATC } \\
\text { CTTTTTTCAGATCTGCGCTCC }\end{array}$ & $(A G)_{13}$ & 172 \\
\hline RM242 & 9 & $\begin{array}{l}\text { GGCCAACGTGTGTATGTCTC } \\
\text { TATATGCCAAGACGGATGGG }\end{array}$ & $(\mathrm{CT})_{26}$ & 225 \\
\hline RM228 & 10 & $\begin{array}{l}\text { CTGGCCATTAGTCCTTGG } \\
\text { GCTTGCGGCTCTGCTTAC }\end{array}$ & $(\mathrm{CA})_{6}(\mathrm{GA})_{36}$ & 154 \\
\hline RM224 & 11 & $\begin{array}{l}\text { ATCGATCGATCTTCACGAGG } \\
\text { TGCTATAAAAGGCATTCGGG }\end{array}$ & $(\mathrm{AAG})_{8}(\mathrm{AG})_{13}$ & 157 \\
\hline RM28502 & 12 & $\begin{array}{l}\text { CGAGCAGATCTGATGTCGTCTTCC } \\
\text { CTTTGCTTTTCATGCCTCACG }\end{array}$ & $(\mathrm{GA})_{26}$ & 155 \\
\hline
\end{tabular}

Table 3. Allele number, number of polymorphic alleles, number of band patterns and PIC values of the SSR markers.

\begin{tabular}{lcccc}
\hline Name of Primer & $\begin{array}{c}\text { Number of } \\
\text { alleles }\end{array}$ & $\begin{array}{c}\text { Number of polymorphic } \\
\text { alleles }\end{array}$ & $\begin{array}{c}\text { Number of } \\
\text { Band patterns }\end{array}$ & $\begin{array}{c}\text { Polymorphic Information } \\
\text { Content (PIC) }\end{array}$ \\
\hline RM526 & 6 & 6 & 7 & 0.349 \\
RM5639 & 8 & 8 & 8 & 0.835 \\
RM334 & 5 & 5 & 5 & 0.655 \\
RM314 & 4 & 4 & 5 & 0.580 \\
RM234 & 2 & 2 & 2 & 0.498 \\
RM407 & 3 & 3 & 3 & 0.217 \\
RM242 & 4 & 4 & 4 & 0.4896 \\
RM228 & 3 & 3 & 5 & 0.319 \\
RM224 & 3 & 3 & 5 & 0.439 \\
RM28502 & 5 & 5 & 5 & 0.569 \\
Total & 43 & 43 & - & - \\
Average & 4.3 & 4.3 & 4.9 & 0.495 \\
\hline
\end{tabular}




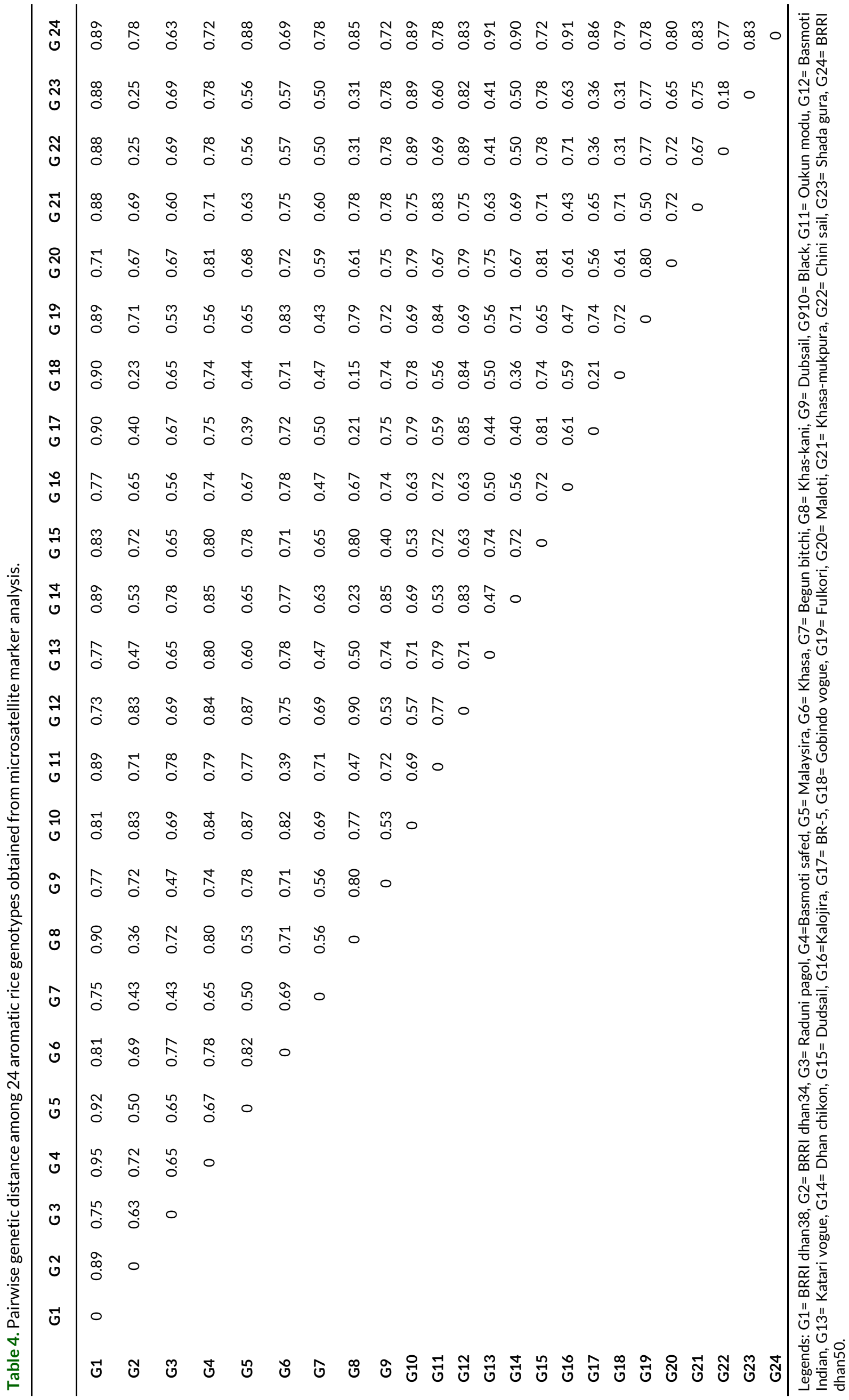


dhan50. All the genotypes in a particular cluster showed higher distance with the genotypes in another cluster, which indicate the presence of wide diversity amongst genotypes of different cluster (Table 4). This also indicate the homogeneous nature of the rice genotypes present in the same cluster. The results were supported by the findings of Iftekharuddaula et al. (2002), Rahman et al. (2012) and Islam et al. (2017).

\section{Pairwise genetic dissimilarity}

A dissimilarity matrix constructed based on Jaccard's coefficient (Table 4.). It was used to determine the level of genetic dissimilarity among the cultivars studied. The pairwise genetic dissimilarity matrix indicated that the highest genetic dissimilarity was found 0.95 between the genotypes BRRI dhan38 and Bashmoti safed. This pair were followed by BRRI dhan38 and Malaysira (0.913), Khas-kani and Basmoti Indian (0.90), BRRI dhan38 and BR-5(0.90), Katarivogue and BRRI dhan50 (0.90), Kalojira and BRRI dhan50 (0.90), Dhan chikon and BRRI dhan50 (0.90) BRRI dhan38 and Khas-kani (0.895), BRRI dhan38 and Gobindo vogue (0.895), Black and BRRI dhan50 (0.895), BRRI dhan38 and Oukunmodu (0.889), Basmoti Indian and Chinisail (0.889), Black and Chinisail (0.889), BRRI dhan38 and BRRI dhan34 (0.889), BRRI dhan38 and Dhanchikon (0.889), BRRI dhan38 and Fulkori (0.889), Black and Sada gura (0.889), BRRI dhan38 and BRRI dhan50 (0.889), BRRI dhan38 and Khasamukpura (0.882), BRRI dhan38 and Chinisail (0.882), BRRI dhan38 and Sada gura (0.882), Malaysira and Basmoti Indian (0.87), Malaysira and BRRI dhan50 (0.875), Malaysira and Black (0.87), Basmoti Indian and BR-5 (0.85), Basmoti safed and Dhancikon (0.85), Khas-kani and BRRI dhan50 (0.85) and so on. The pairwise genetic dissimilarity matrix indicated that the lowest genetic dissimilarity was found 0.15 between the genotypes Kash-kani and Gobindo vogue. This pair were followed by the genotypes Chinisail and Sadagura (0.18), BR-5 and Gobindovogue (0.21), Kash-kani and BR-5 (0.21), Kash-kani and Dhanchikon (0.23), BRRI dhan34 and Chinisail (0.25), BRRI dhan34 and Sadagura (0.25). The pair wise genetic dissimilarity co-efficient indicated high genetic distance among most of the aromatic rice genotypes. Among them five rice genotypes (BRRI dhan38, BRRI dhan50, Bashmoti safed, Malaysira, Khas-kani) which showed highest genetic distance, might be utilized as possible parents for the development of fine grain aromatic rice varieties. High genetic distance between the aromatic rice genotypes cultivated in Bangladesh was also reported by Sajib et al. (2012). Similarly, high genetic distance was reported by Islam et al. (2017) in their genetic diversity assessment of 53 aromatic rice genotypes cultivated in Bangladesh using 16 quantitative traits.

\section{Conclusion}

In conclusion, molecular characterization of Bangladeshi aromatic rice landraces exposed that great variation exists amongst the aromatic rice genotypes. The genetic diversity preserved in these aromatic rice gene pool could be a valuable resource for further improvement and developing new varieties.

\section{ACKNOWLEDGEMENTS}

We gratefully acknowledge the assistance of the Biotechnology Division, BINA, Mymensingh, Bangladesh in conducting this research work at the Biotechnology Laboratory, for technical support and providing the seed samples. We would like to express our appreciation to GRC, Bangladesh Rice Research Institute (BRRI) for their cooperation in providing the seed samples.

\section{Conflict of interest}

The authors declare that they have no conflict of interest regarding the materials used in this manuscript.

Open Access: This is open access article distributed under the terms of the Creative Commons Attribution License, which permits unrestricted use, distribution, and reproduction in any medium, provided the original author(s) and the source are credited.

\section{REFERENCES}

Anderson, J.A., Churchill, G.A., Autrique, J.E., Tanksley, S.D. and Sorrells, M.E. (1993). Optimizing parental selection for genetic linkage maps. Genome, 36(1): 181-186, https:// doi.org/10.1139/g93-024

Anonymous (2018). Productivity in global rice environments. Retrieved from http://ricepedia.org/rice-as-a-crop/riceproductivity on August 5, 2018.

Chakravarthi, B.K. and Naravaneni, R. (2006). SSR marker based DNA fingerprinting and diversity study in rice (Oryza sativa. L). African Journal of Biotechnology, 5(9): 684-688.

Choudhury, B., Khan, M.L. and Dayanandan, S. (2013). Genetic structure and diversity of indigenous rice (Oryza sativa) varieties in the Eastern Himalayan. Springer Plus, 2: 228234, https://doi.org/10.1186/2193-1801-2-228

Garcia-Vallvé, S., Palau, J. and Romeu, A. (1999). Horizontal gene transfer in glycosyl hydrolases inferred from codon usage in Escherichia coli and Bacillus subtilis. Molicular Biology and Evolution, 16: 1125-1134, https://doi.org/10.1093/ oxford journals.molbev.a026203

Garris, A.J., Tai, H.T., Coburn, J., Kresovich, S. and McCouch, S. (2005). Genetic structure and diversity in Oryza sativa L. Genetics, 169: 1631-1638, https://doi.org/10.1534/ genetics.104.035642

Hossain, M.M., Islam, M.M., Hossain, H., Ali, M.S., Teixeira da Silva, J.A., Komamine, A. and Prodhan, S.H. (2012). Genetic diversity analysis of aromatic landraces of rice (Oryza sativa L.) by microsatellite markers. Genes, Genomes and Genomics, 6(SI1): 42-47.

Iftekharuddaula, K.M., Akter. K., Bashar, M.K. and Islam, M.R. (2002). Genetic parameters and cluster analysis of analysis of panicle traits in irrigated rice. Bangladesh Journal of Plant Breeding and Genetics, 15: 49-55.

Islam, M.Z., Khalequzzaman, M., Bashar, M.K., Ivy, N.A., Haque, M.M. and Mian M.A.K. (2016). Variability assessment of 
aromatic and fine rice germplasm in Bangladesh based on quantitative traits. The Scientific World Journal, 2796720, https://doi.org/10.1155/2016/2796720

Islam, M.M.U., Saha, P.S., Chakrobarty, T., Saha, N.K., Islam, M.S. and Salam, M.A. (2017). Genetic diversity of aromatic rice in Bangladesh. Research in Agriculture Livestock and Fisheries, 4(1): 1-6.

Khush, G.S. (2000). Taxonomy and origin of rice. In: Singh, R.K., Singh, U.S., Khush, G.S. (Eds), Aromatic rices. Oxford \& IBH, New Delhi, pp 5-13.

Li, C., Zhang, Y., Ying, K., Liang, X. and Han, B. (2004). Sequence variation of simple sequence repeated on chromosome 4 in two subspecies of Asian cultivated rice. Theoretical and Applied Genetics, 108: 392-400, https://doi.org/10.1007/ s00122-003-1457-z

Ma, H., Yin, Y., Guo, Z.F., Chen, L.J., Zhang, L., Zhong, M. and Shao, G.J. (2011). Establishment of DNA fingerprinting of Liaojing series of japonica rice. Middle-East Journal of Science Research, 8(2): 384-392.

McCouch, S.R., Teytelman, L., Xu, Y., Lobos, K.B., Clare, K., Walton, M., Fu, B., Maghirang, R., Li, Z., Xing, Y., Zhang, Q., Kano, I., Yano, M., Fjellstrom, R., De Clerk, G., Schneider, D., Cartinhour, S., Ware, D. and Stein, L. (2002). Development and mapping of 2240 new SSR markers for rice (Oryza sativa L.). DNA Research, 9(6): 199-207, https:// doi.org/10.1093/dnares/9.6.199

Nei, M. (1973). Analysis of gene diversity in subdivided populations. Proceedings of the National Academy of Sciences of the United States of America, 70 (12): 3321-3323, https:// doi.org/10.1073/pnas.70.12.3321

Rahman, M.M., Rasaul, M.G., Hossain, M.A., Iftekharuddaula, K.M. and Hasegawa, H. (2012). Molecular characterization and genetic diversity analysis of rice (Oryza sativa L.) using SSR markers, Journal of Crop Improvement, 26(2): 244-257, http://dx.doi.org/10.1080/ 15427528. 2011.627533

Roy, S., Banerjee, A., Mawkhlieng, B., Misra, A.K., Pattanayak, A., Harish, G.D. (2015). Genetic diversity and population structure in aromatic and quality rice (Oryza sativa L.) landraces from North Eastern India. PLOS ONE, 10(6): e0129607. http://dx.doi.org/10.1371/ journal.pone.0129607

Sajib, A.M., Musharaf, M.H., Mosnaz, A.T.M.J., Hossain, H., Islam, M.M., Ali, M.S. and Prodhan, S.H. (2012). SSR marker-based molecular characterization and genetic diversity analysis of aromatic landreces of rice (Oryza sativa L.). Journal of Bioscience and Biotechnology, 1(2): 107-116.

Singh, R.K., Singh, U.S. and Khush, G.S. (2000). Prologue. In: Singh, R.K., Singh, U.S. and Khush, G.S. (Eds), Aromatic rices. Oxford \& IBH, New Delhi, pp 1-4.

Stein, N., Herren, G. and Keller, B. (2001). A new DNA extraction method for high-throughput marker analysis in a large- genome species such as Triticum aestivum. Plant Breeding, 120(4): 354-356, https://doi.org/10.1046/j. 14390523.2001.00615.x

Weber, D.J., Rohilla, R. and Singh, U.S. (2000). Chemistry and biochemistry of aroma in scented rice. In: Singh, R.K., Singh, U.S. and Khush, G.S. (Eds), Aromatic rices. Oxford \& IBH, New Delhi, pp 39-40.

Wong, S.C., Yiu, P.H., Bong, S.T.W., Lee, H.H., Neoh, P.N.P. and Rajan, A. (2009). Analysis of Sarawak Bario rice diversity using microsatellite markers. American Journal of Agricultural and Biological Sciences, 4(4): 298-304, https:// doi.org/10.3844/ajabssp.2009.298.304 